\title{
Electron beam generation by electron multiplication
}

\author{
C. Murray, B. Szapiro, ${ }^{\text {, }}$ and J. J. Rocca ${ }^{\text {b; }}$ \\ Electrical Engineering Department, Colorado State University, Fort Collins, Colorado 80523
}

(Received 13 February 1989; accepted for publication 27 March 1939)

We have demonstrated that iniense pulsed electron beams can be created by multiplication of lower current elcctron streams impinging on a high electron yield target. A 17 A electron beam of $1 \mu \mathrm{s}$ pulse width was generated from a $2.5 \mathrm{~A}$ beam bombarding an activated Ag-Mg target $2.5 \mathrm{~cm}$ in diameter.

We have demonstrated a new approach for the generation of broad-area intense electron beams based on the multiplication of electron streams achieved by bombarding highyield materials. This well known phenomenon has been employed for decades in photomultiplier detectors to amplify currents in the submilliamp range,' but to our knowlcoge has never been used for the generation of intense elecrron bcams. We report the generation of broad-area electron beam pulses of $1 \mu$ s duration with current densities up to 3.4 $\mathrm{A} / \mathrm{cm}^{2}$ by single-stage muliplication of a $0.5 \mathrm{~A} / \mathrm{cm}^{2}$ electron stream. The scheme has the potential of generating intense electron beams whose current and pulse wich th are tailored by controlling a low current density beam.

Ion and photon fluxes have been previously used to cause intense electron emission from cold cathodes. The emission of electrons from cathode materiais following the bombardment by energetic ions has been widely used in the generation of broad-area electron beams. ${ }^{2-7}$ While many cathode materials exist which present high electron yields following the bombardment by jons, ${ }^{8,9}$ ion bombardment electron guns have limitations for the generation of very high current density beams. For a given electron yield, the elestron beam current density is limited by the bombarding ion Dux, which is itself limited by the large positive space charge. Also, ion bombardment induced sputtering of the cathode material is an undesirable effect that is present and limits the elcctron gun lifetime. Recently, very large electron beam current densities have been achieved using photocathodes. 10.11 The photoemission scheme has the advantages that photons do not present space-charge limitations or cause sputtering. An additional advantage of photocathodes is the very small energy spread of the emitted beam produced by monochromatic irradiation. However, the laser required as a photon source increases the size and complexity of the cathode, and also limits its scaling to very broad areas.

In the experiments reported herein, an electron beam was generaled by electron bombardment induced emission of an activated Ag-Mg target $2.5 \mathrm{~cm}$ in diameter. In this scheme the elcctrons cmitted by a low current density primary electron source impinge on a high electron yick target at an energy close to that required for maximum emission of secondary electrons. The secondary electrons are subsequenty accelstated in the opposite direction to form a higher current density beam. Electrons cause negligible sputter-

\footnotetext{
' Postdoctoral Fellow, Univessiry of Buenos Aires.

"Nationai Seince Foundation Presidential Young Investigator.
}

ing and create a space charge which is two orders of magnitude lower than that corresponding to an ion beam of the same fux and energy. The experiments reported in this letter show that some of the same materials and surface activation procedures developed for electron multiplication of the microamp level in photomultiplier tubes allow for effcient electron multipication at current densities many orders of magnitude larger. Consequently, the scheme reported herein has the potential of generating very high current density electron beams.

The setup used to demonstrate this electron beam generation scheme is represented in Fig. 1. The primary, or seed, electron boam pulse is generated from a 2.5 -cm-diam thermionic dispenser cuthode, by puising an accelerating grid to positive potential with respect to the cathode and foating them negatively with respect to a grounded grid. The beam propagates to another grounded grid placed in close proximity with the target. The target is negitively biased with respect to ground to retard the electrons from the seed beam, such that they will bombard its surface with an energy close to that necessary for maximum electron yicld (about $1 \mathrm{keV}$ for Ag-Mg targets). Electron beam multiplication has been achieved using an activated Ag (98.3\%)-Mg (1.7\%) polycrystalline aloy target. The target and its corresponding grounded grid are positioned forming an angle with respect to the axis of the primary beam, either $11^{\circ}$ or $30^{\circ}$ in the experiments reported herein, to allow extraction of the secondary beam as it will be required in practical applications. An additional benefit of this configuration is that the electron yield is slightly increased with respec: to the normal incidence value. The entire setup is enclosed in a stainless-steel chamber $20 \mathrm{~cm}$ in diameter that is evacuated to a pressure of $1 \times 10^{-7}$ Torr using a turbomolecular pump. In the electron

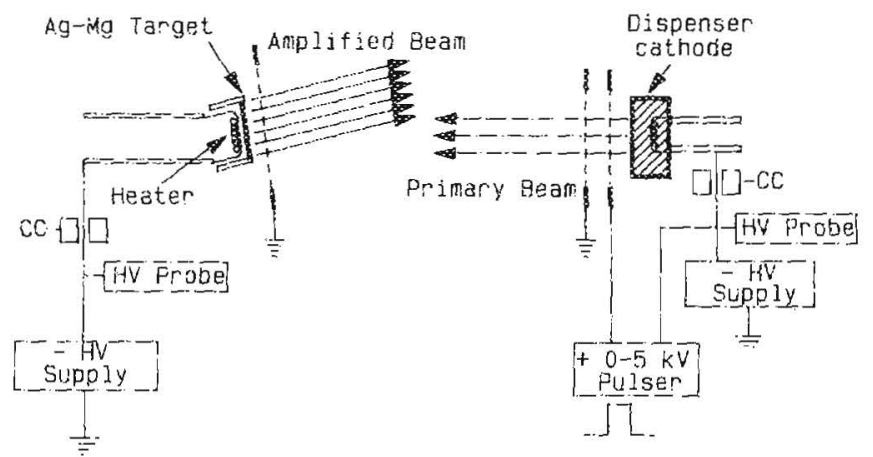

EIC. 1. Schematic representation of clectron multiplication sctup. Current coils are ideitified by CC. The vacuum chamber is not shown. 
multiplication experiments the chamber is filled with $5 \times 10^{-4}$ Torr of argon to provide quasincutralization of the electron streams and thereby overcome the current imitations set by the propagation of unneutralized electron beams of less than $10 \mathrm{keV}$ in an equipotential region. ${ }^{2}$

The Ag-Mg larget surface was activated to obtain large electron yields following a procedure developed to activate dynodes of photonultiplier tubes made of the satne materia. " The procedure consists in diffusing $M g$ to the surface by heating the target and achicving oxidation in a $\mathrm{CO}$, aimosphere to form a magnesium oxide layer. Faibre to activate the target surface was observed to yield multiplication factors of less than 2. After the target temperature was increased to $750^{\circ} \mathrm{C}$ and exposed for 2 min to an atmosphere of $400 \mathrm{~m}$ Torr of $\mathrm{CO}$, yields of five were consistently observed and yields up to seven have been occasionally measured. Higher yiclos might resulf from the optimization of the thickness of the oxide layer; a systematic optimization of the activation procedure has not yei been completed.

In Fig. 2 the oscilloscope traces show the effect of electron multiplication. The top trace corresponds to the current pulse collected at the grounded target when bombarded by an $8 \mathrm{keV}$ primary beam impinging at at angle of $30^{\circ}$. In this situation the sccondary clectrons rapidly form a space charge that inhibits significant electron emission and consequently the target current can be consiciercd a good approximation of the primary beam current impinging on the target if backscattering is neglected. ${ }^{14}$ This assumption was verified by applying a $50 \mathrm{~V}$ positive bias to the target, in which case the current changed by less than $15 \%$. The botton trace is the measured turget current when all conditions are maintained equal, but the target is biased to $-5 \mathrm{kV}$. In this situation the primary electrons arrive at the target surface with an cnergy of $3 \mathrm{keV}$ and the secondary electrons are accelerated to form a $5 \mathrm{keV}$ beam. The bottom trace is the sum of the primary beam current arriving to the target and that of the emitted secondary electron current. Figure 2 shows that for

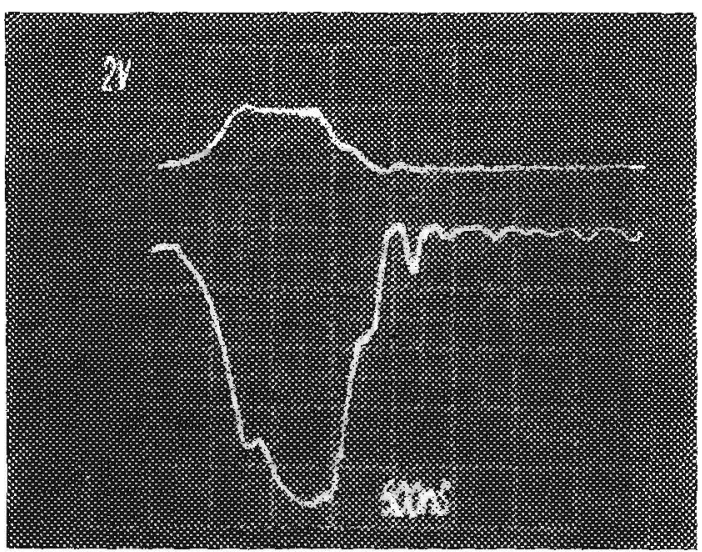

FIG. 2. Current lowing io the Ag-Mg target isombarded with an $8 \mathrm{keV}$ electron beam when the target is grounded (uppertrace, $2 \mathrm{~A} /$ div) and when it is biased to $-5 \mathrm{kV}$ (lower trice. $2 \mathrm{~A} / \mathrm{div}$ ). The lower pulse represents the sum of the primary beam current coliected (positive current) and the emited current (negative current). The background pressure of argon is $5 \times 10^{-\cdots}$ rorr. The angle between the normal to the target and the axis of the prinary beam is $30^{\circ}$, and the disiance between grounded grids is $8=\mathrm{cm}$. a primary beam current of $2 \mathrm{~A}$ a secondary beam current of 11 A was emitted, corresponding to a multiplication factor of 5.5. The shape of the multiplied clectron pulse is observed to follow that of the 1 fis primary beam. Impinging on the target with a current of $2.5 \mathrm{~A}\left(0.5 \mathrm{~A} / \mathrm{cm}^{2}\right)$ produced $17 \mathrm{~A}$ $\left(3.4 \mathrm{~A} / \mathrm{cm}^{\prime}\right)$ of emitted current when the primary beam had an energy of $8 \mathrm{keV}$ and the target was floated to $-4 \mathrm{kV}$.

Figures 3 ( a) and 3 (b) show the electron multiplication factors measured as a function of the energy of the primary electrons, for primary bean current densities of 0.3 and 0.6 $A / \mathrm{cm}^{2}$, respectively, impinging at angle of $11^{\circ}$. In both cases the ectron yield is observed to increase from approximately one for a $9 \mathrm{kcV}$ primary electron energy to nearly five for a primary electron energy of about $3 \mathrm{keV}$. No degradation of the yields was observed to occur after hours of bombardment with $\mu$ s-long electron beam pulses al a frequency of $1 \mathrm{~Hz}$. Increasing the magnitude of the negative voltage bias of the target such that the primary electrons would arrive at the target surface with an energy of less than the smallest value shown in Fig. 3 would probably result in further increase in the yield; however, this was observed to distort the current pulse due to the onset of oscillations.

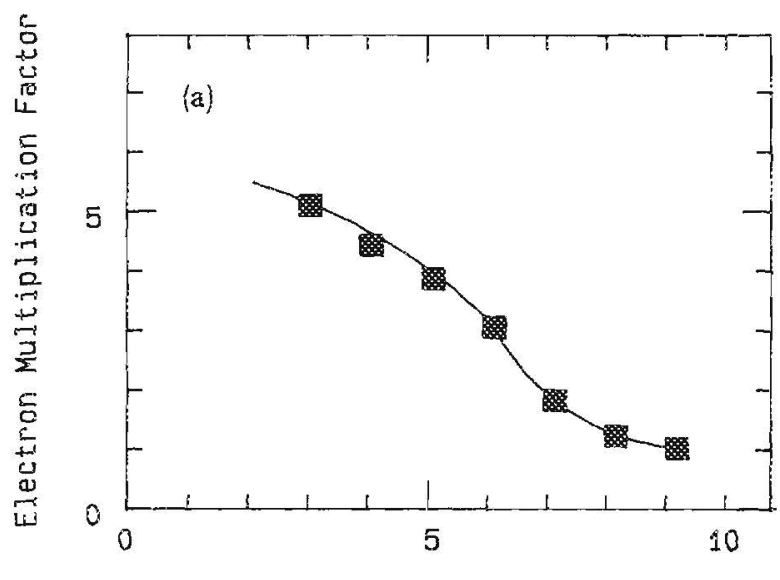

Energy of Impinging Electrons (KeV)

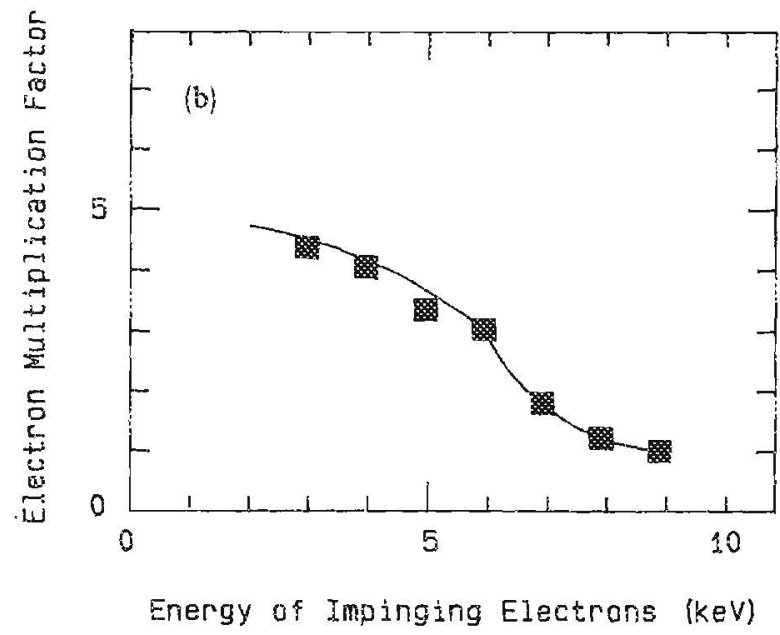

FIG. 3. Electron multiplication tactors as a function of impinging electron energy for an input current of (a) 1.5 and (b) $3.0 \mathrm{~A}$. The angle between the normal to the target surface and the primary beam is $11^{\circ}$, and the distance between grounded grids is $14 \mathrm{~cm}$. 


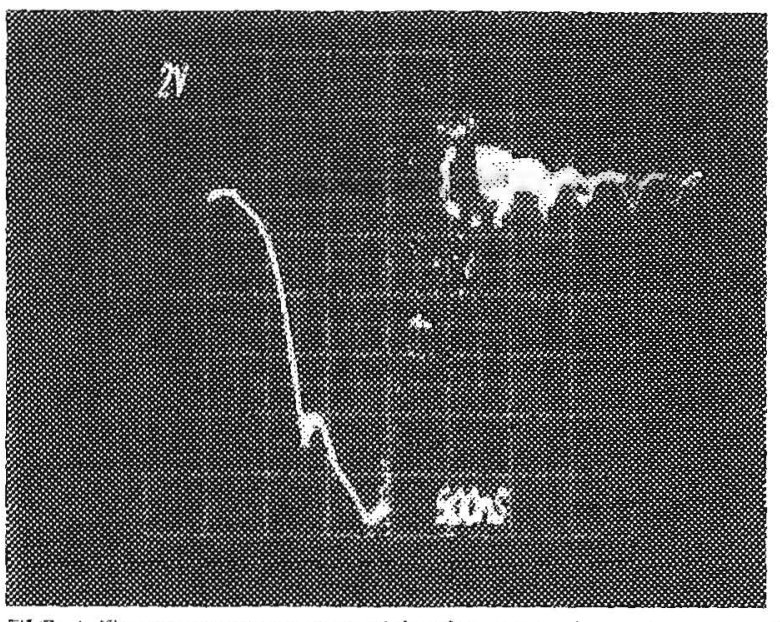

F10. 4. Tarzet current measured for hie same primary beam conditions of Mig. 2 bui biasing the target to $-5.2 \mathrm{kV}$. Oscifletions are observed to oceur at the end of the emitted current pulse

Figure 4 illustrates the onset of the oscillation for the same primary beam conditions of Fig. 2, occurring when the magnituate of the bias is increased by $200 \mathrm{~V}$ to $-5.2 \mathrm{kV}$. The emitted target current increases to $13 \mathrm{~A}$, corresponding to an electron multiplication factor of 6.5 , before the current pulse is distupted by oscillations. If the observed instabilities are avoided, it should be mossible to achieve significantly larger electron bean currents than those reported herein. The nutire of the observed instabilities has not yei been studied, but they could be due to electron-ion oschllations known to occur in the propagation of guasi-neutralized electron beam. ${ }^{15-17}$ If this is the cause, the onset of the instability could be shifted to higher current vaiues by increasing the clectron beam acceleration potential, ${ }^{15} .17$ which in the current experiment was limitcd to less than $10 \mathrm{kV}$.

In summary, we have achieved single-stage electron multiplication by a factor $>5$ for $1 \mu$ s pulses at current den- sities more than three orders of magnitude larger than those produced in photomultiplier tubes. Electron muliplication in high yield targets has the potential of producing intense electron beams.

This work was supported by Wright Patterson Air Force Base. J. J. Rocea acknowledges the support of a $\mathrm{Na}$ tionai Science Foundation Presidential Young Investigators Award.

'V. K. Z,woykin and E. G. Ramberg, Photselectricity and its Applications. (Wiley, New York, 1949).

'G. W. Mcciure, Phys. Re 124, 969 (1961).

'R. A. Dugdale, J. Marer. Sci. 10. 896 (1975).

'J. J. Kocca, J. D. Meyer. M. R. Farreil. and G. J. Collins. J. Appl. Phys. 56, $790(1984)$

'W. M. Clark, Jr. and G. J. Dunning, J. Quantum Elecron. QR-14. 126 (1978).

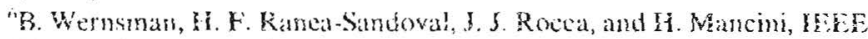
Trans. Plasna Sci PS 14.518 (1986).

H. F. Ranca-Sandoval, N. Reesor, B. T. Szapin, C. Murcay, and 3.3. Rocea, IFFE Trans. Plasma Sci. PS.15, 361 (1987).

"H. C. Bourne Ji., R. W. Cloud, and I. G. Trunip. J. Appl. Phys. 26, 596 (1955).

"B. Szapiro, 3. J. Rocea, and! T. Prabhuram, Appl. Phys. Lett. 33, 358 (1988).

"Chutghsin Lece. Appl. Phys. F.ctt. 44, 565 (1983).

"C. H. Lee and P. E. Oetinger, IEEE Trans. Nuel. Sc AS-32. 3045 (1985).

J. R. Pierce. Theory and Design of Electm Bcam. (Van Nosirand, New Jersey, 1954).

'B. Wargo, B. V. Buxby, and W. (.) Shepherd, J. Appl. Phys. 27, 1311 (1956).

1.tElecton backscatceing for a magnesium uxicie surface should be of the order of $10 \%$. .. N. Lxebretsov and M. V. Gomoyunova, Emission Elecironics (Keter, Jerusalcni. \{971\}, p. 254.

'J. K. Yieree, J. Appl Phys, 19, 23! (1947).

"Y. D. Fedorchenko, B. N. Rutkevich, V. I. Muratov, and B. M. Chemyi, Sos. Phys. Tech. l'hys 7, $696(196.3)$.

"M. V. Nexlin, M. I. Taktakishivili, and A. S. Trubnikov, Sov l'hys. IET? 33, $548(1971)$. 